\title{
The prevalence and related factors of fatigue in patients with COPD: a systematic review
}

\author{
Zjala Ebadi $\mathbb{1}^{1,11}$, Yvonne M.J. Goërtz ${ }^{2,3,4,11}$, Maarten Van Herck $\mathbb{1}^{2,3,4,5}$, Daisy J.A. Janssen $\mathbb{1}^{2,6}$, \\ Martijn A. Spruit (10),3,4, Chris Burtin ${ }^{5}$, Melissa S.Y. Thong ${ }^{7}$, Jean Muris ${ }^{8}$, Jacqueline Otker ${ }^{9}$, \\ Milou Looijmans ${ }^{1}$, Christel Vlasblom ${ }^{1}$, Joëlle Bastiaansen ${ }^{1}$, Judith Prins ${ }^{1}$, Emiel F.M Wouters ${ }^{3,10}$, \\ Jan H. Vercoulen ${ }^{1}$ and Jeannette B. Peters ${ }^{1}$
}

\begin{abstract}
${ }^{1}$ Dept of Medical Psychology, Radboud University Medical Center, Radboud Institute for Health Sciences, Nijmegen, The Netherlands. ${ }^{2}$ Dept of Research and Development, Ciro, Horn, The Netherlands. ${ }^{3}$ Dept of Respiratory Medicine, Maastricht University Medical Centre (MUMC+), Maastricht, The Netherlands. ${ }^{4}$ NUTRIM School of Nutrition and Translational Research in Metabolism, Maastricht, The Netherlands. ${ }^{5}$ REVAL - Rehabilitation Research Center, BIOMED - Biomedical Research Institute, Faculty of Rehabilitation Sciences, Hasselt University, Diepenbeek, Belgium. ${ }^{6}$ Dept of Health Services Research, Care and Public Health Research Institute, Faculty of Health Medicine and Life Sciences, Maastricht University, Maastricht, The Netherlands. ${ }^{7}$ Dept of Medical Psychology, Amsterdam University Medical Centers, location AMC, Amsterdam, The Netherlands. ${ }^{8}$ Dept of Family Medicine, CAPHRI Care and Public Health Research Institute, Maastricht University, Maastricht, The Netherlands. ${ }^{9}$ Patient Advisory Board, Ciro, Horn, The Netherlands. ${ }^{10}$ Ludwig Boltzmann Institute for Lung Health, Vienna, Austria. ${ }^{11}$ Joint first authors.
\end{abstract}

Corresponding author: Zjala Ebadi (Zjala.Ebadi@radboudumc.nl)

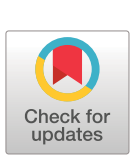

CThe authors 2021 .

This version is distributed under the terms of the Creative Commons Attribution Non-Commercial Licence 4.0. For commercial reproduction rights and permissions contact permissions@ersnet.org

This article has supplementary material available from err.ersjournals.com

Received: 15 Sept 2020 Accepted: 4 Jan 2021

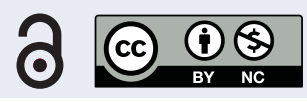

Shareable abstract (@ERSpublications)

Fatigue is an important symptom in COPD. In the 196 evaluated studies, prevalence of fatigue ranged from $17-95 \%$. Physical, psychological and demographic factors are associated with fatigue in COPD. Further studies are needed to evaluate these underlying factors. https://bit.ly/3q2BRcE

Cite this article as: Ebadi Z, Goërtz YMJ, Van Herck M, et al. The prevalence and related factors of fatigue in patients with COPD: a systematic review. Eur Respir Rev 2021; 30: 200298 [DOI: 10.1183/ 16000617.0298-2020].

\section{Abstract}

Background Fatigue is a distressing symptom in patients with COPD. Little is known about the factors that contribute to fatigue in COPD. This review summarises existing knowledge on the prevalence of fatigue, factors related to fatigue and the instruments most commonly used to assess fatigue in COPD.

Methods Pubmed, PsycINFO, EMBASE, Cochrane and CINAHL databases were searched for studies from inception up to 7 January 2020 using the medical subject headings “COPD” and "Fatigue”. Studies were reviewed in accordance with PRISMA guidelines.

Results 196 studies were evaluated. The prevalence of fatigue ranged from 17-95\%. Age ( $\mathrm{r}=-0.23$ to $\mathrm{r}=0.27)$, sex $(\mathrm{r}=0.11)$, marital status $(\mathrm{r}=-0.096)$, dyspnoea $(\mathrm{r}=0.13$ to $\mathrm{r}=0.78)$, forced expiatory volume in $1 \mathrm{~s} \%$ predicted $(\mathrm{r}=-0.55$ to $\mathrm{r}=-0.076$ ), number of exacerbations $(\mathrm{r}=0.27$ to $\mathrm{r}=0.38$ ), number of comorbidities $(r=0.10)$, number of medications $(r=0.35)$, anxiety $(r=0.36$ to $r=0.61)$, depression $(r=0.41$ to $r=0.66)$, muscle strength ( $r=-0.78$ to $r=-0.45$ ), functional capacity ( $r=-0.77$ to $r=-0.14$ ) and quality of life ( $\mathrm{r}=0.48$ to $\mathrm{r}=0.77$ ) showed significant associations with fatigue.

Conclusions Fatigue is a prevalent symptom in patients with COPD. Multiple physical and psychological factors seem to be associated with fatigue. Future studies are needed to evaluate these underlying factors in integral analyses in samples of patients with COPD.

\section{Introduction}

COPD is characterised by persistent airflow limitation [1]. After dyspnoea, the feeling of fatigue is the second most important complaint in patients with COPD [2]. Patients with COPD describe their fatigue as a feeling of "general tiredness" [3] or as a feeling of being "drained of energy" [4]. Fatigue can have major consequences on health status, as it may restrict patients' daily activities, lead to a worsened prognosis and is a predictor of mortality [5].

Despite its high prevalence and negative impact on daily life, fatigue often remains unrecognised and untreated. If fatigue is not treated, it can worsen over time, even though the degree of airflow limitation 
remains stable [6]. In order to develop effective interventions aimed at stabilising or reducing fatigue, it is important to know which factors precipitate and perpetuate fatigue in COPD. Fatigue is thought to be the result of complex interactions between various physiological and psychological processes [5, 7]. To date, several studies have investigated factors associated with fatigue [6, 8-16]. However, these studies differ greatly in their definitions and assessment methods of fatigue and in sample selection. In addition, many of these studies did not assess fatigue as their primary outcome, complicating the comparison of results. LEWKo et al. [17] reported in 2012 that a combination of exercise capacity, muscle strength, airflow limitation, depression, dyspnoea and sleep quality is associated with fatigue in patients with COPD. In recent years, the number of studies on fatigue has increased drastically, providing evidence for the need of an updated review on the prevalence and predictors of fatigue. Therefore, the aim of this literature review is to summarise the existing knowledge about fatigue in patients with COPD by examining the prevalence of fatigue and its association with physical, psychological, social and behavioural factors. Additionally, this review summarises the instruments that were most commonly used to assess fatigue.

\section{Methods}

\section{Protocol and registration}

This systematic review was conducted in accordance with the PRISMA statement for systematic reviews and meta-analyses [18]. A detailed protocol is published in the International Prospective Register of Systematic Reviews (PROSPERO: 42017068136).

\section{Search strategy}

Pubmed, PsycINFO, EMBASE, Cochrane and CINAHL literature databases were searched using the following medical subject headings $(\mathrm{MeSH})$ and free text search terms: 1) COPD; and 2) fatigue (exhaustion, tiredness, energy loss, mental fatigue). The search was conducted in December 2018 and was updated in January 2020. There were no restrictions on publication period.

\section{Study selection}

Two reviewers (Z. Ebadi and Y.M.J. Goërtz) independently assessed the eligibility of articles based on title and abstract. In cases of disagreement, a third reviewer (J.H. Vercoulen) was consulted. The eligibility criteria for inclusion were: 1) all study types with quantitative data examining fatigue in COPD at baseline; 2) studies that used fatigue as either a primary or secondary outcome; 3) a full-report in English, Dutch or German.

Studies focusing on muscle fatigue were excluded from this review. Intervention studies that met eligibility criteria were included and only the baseline data were used.

\section{Data extraction}

The baseline data on the prevalence of fatigue and demographic, physical, psychological, and behavioural factors related to subjective fatigue were independently extracted by two researchers (Z. Ebadi and Y.M.J. Goërtz) using a predefined extraction form in MS Excel (Microsoft, Redmond, WA, USA). The magnitude of the relationships was interpreted using the effect size provided by CoHEN [19]. Correlation coefficients (r) in the order of $\leqslant 0.10$ represent a small association, coefficients of $0.10-0.30$ are a medium association, and coefficients of $\geqslant 0.50$ represent a large correlation. Furthermore, where necessary, the authors of papers were contacted for additional information on prevalence of fatigue in COPD.

\section{Results}

The search identified 5637 potentially relevant papers; 3610 after removing duplicates. Of these, 3095 papers were excluded after screening the titles and abstracts. In the end, 196 of the 516 papers met the inclusion criteria and were included in the current systematic review (figure 1). Of these 196 studies, 18 papers referred to the same data collection. Nevertheless, these are included since the research question and parameters that were studied differed per study.

\section{Study characteristics}

The study characteristics of the included studies are summarised in online supplementary table 1 . The sample size of the studies varied between 10 and 2118 patients with COPD. Of the 196 included studies, 145 were cross-sectional, 46 randomised controlled trials and 5 retrospective. In 90 (45\%) of 196 studies, fatigue was examined as a primary outcome.

\section{Prevalence of fatigue in patients with COPD}

Of the 196 reviewed studies, only 23 studies reported a prevalence rate of fatigue in COPD; prevalence ranged from $17 \%$ to $95 \%$ [6, 16, 20-40] (table 1 and online supplementary table 2). Of these studies, one 


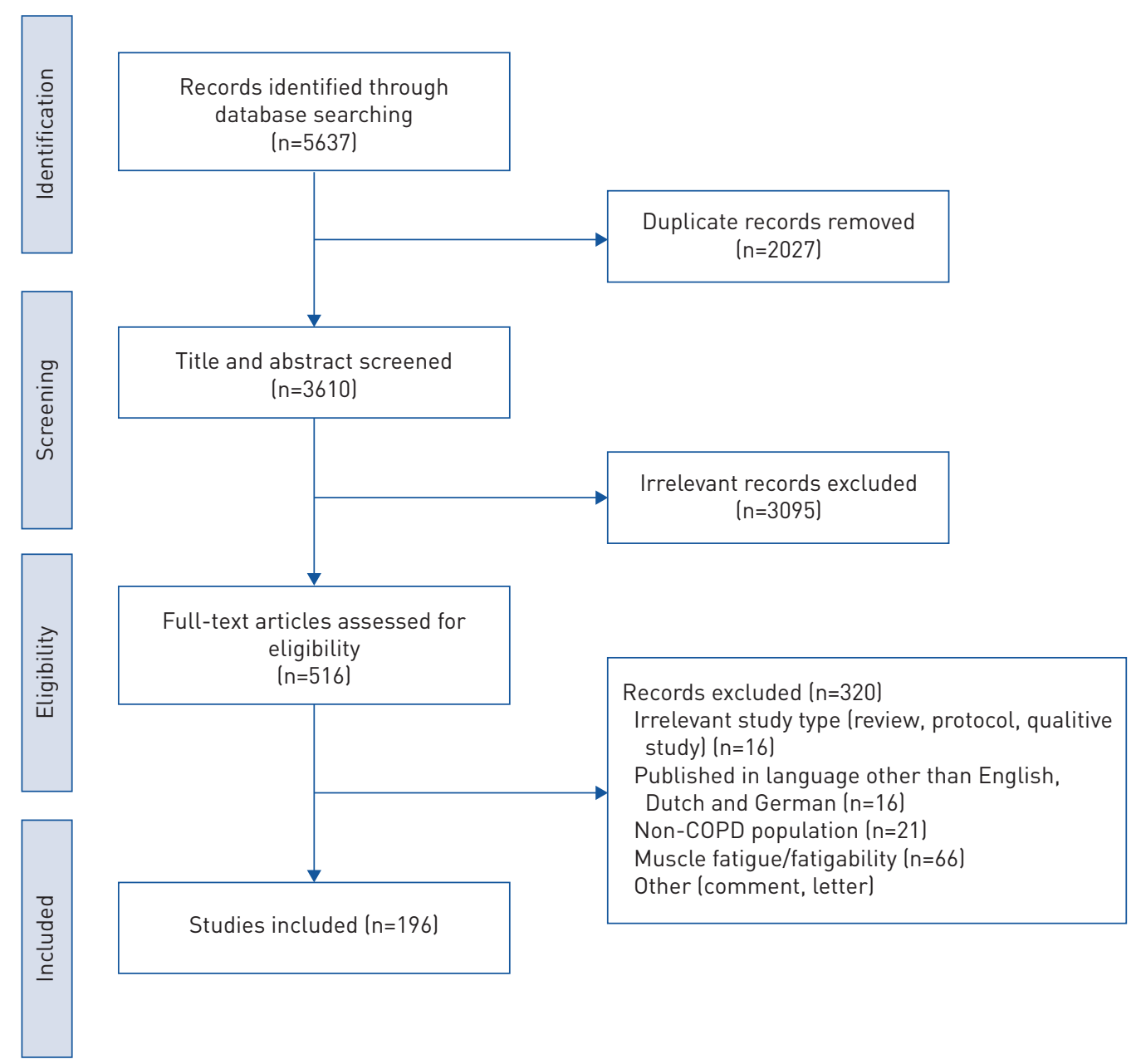

FIGURE 1 PRISMA flow chart.

study was carried out in primary care settings [20], sixteen studies in secondary care settings [6, 16, 21-34], three studies were in pulmonary rehabilitation settings [35-37], two studies in tertiary care settings [38, 39], and one study had a mixed population from secondary and tertiary care settings [40]. Only two studies used validated cut-offs to determine prevalence referring to normal, mild and severe fatigue [6, 27]. Seventeen studies described cut-offs used to determine prevalence rates, but validity information was lacking $[16,20,21,23,24,26,28-35,37,38,40]$. Three studies reported prevalence rates, but any information on how these prevalence rates were obtained or validated were lacking [20, 36, 37]. Eight papers described and compared the prevalence rate of fatigue in non-COPD patients as well as in patients with COPD $[9,11,16,20,27-32]$. Most studies indicated that prevalence of fatigue is significantly higher in patients with COPD compared with controls without COPD [9, 11, 16, 20, 27, 28]. One population-based study did not find a significant difference in fatigue scores between subjects with COPD and controls without COPD [29]. Furthermore, one study reported that the proportion of clinically relevant fatigue was higher in participants with COPD than participants without COPD only in male participants [32].

\section{Sociodemographic factors}

Age

In total, 19 out of 196 studies assessed the link between age and fatigue in COPD [12, 16, 27, 31, 35-38, 41-51], of which 10 studies a significant associations [12, 16, 27, 31, 35, 36, 41, 42, 45, 47] (online supplementary table 3 and figure 2). Nevertheless, all associations were small $(r<0.30)$ and were often contradictory; some studies reported that older patients with COPD experienced more fatigue compared with younger patients [12, 31, 41], whereas other studies observed the opposite [16, 27, 35, 36, 42, 47]. Several studies controlled the association between fatigue and the factor "age" for confounders [31, 38, 46]. 


\section{TABLE 1 Prevalence of fatigue in patients with COPD}

\begin{tabular}{|c|c|c|c|c|c|c|c|c|}
\hline $\begin{array}{l}\text { First author } \\
\text { [ref.] }\end{array}$ & $\begin{array}{c}\text { Fatigue } \\
\text { assessment tool }\end{array}$ & $\begin{array}{l}\text { Sample } \\
\text { size } n\end{array}$ & Responder & $\begin{array}{l}\text { Responders } \\
\text { with fatigue }\end{array}$ & Normal & Mild & Severe & Comments \\
\hline $\begin{array}{l}\text { Peters } \# \text {,थ } \\
{[14]}\end{array}$ & $\begin{array}{l}\text { CIS - subscale } \\
\text { fatigue }\end{array}$ & 168 & Patients with COPD & & 54 & 25 & 21 & \\
\hline BALTZAN $^{+}[30]$ & $\begin{array}{l}\text { SF-36 - vitality } \\
\text { domain }\end{array}$ & 251 & Patients with COPD & & 61 & & 39 & $\begin{array}{l}\text { Patients were divided into } 2 \text { groups } \\
\text { based on scores <2 SD from } \\
\text { published mean age-adjusted } \\
\text { normal vitality scores for general } \\
\text { Canadian population }\end{array}$ \\
\hline WALKE $^{\#, \S}[23]$ & $\begin{array}{l}\text { ESAS - tiredness/ } \\
\text { fatigue symptom }\end{array}$ & 74 & Patients with COPD & & 31 & 19 & 50 & $\begin{array}{l}\text { Normal fatigue is not reported in } \\
\text { study; it is calculated for this } \\
\text { table by subtracting \% of "mild" } \\
\text { and "severe" fatigue from possible } \\
\text { total of } 100 \% \\
\text { Original VAS score modified so } \\
\text { symptoms rated on 4-point scale } \\
\text { (not present, mild, } \\
\text { moderate, severe) } \\
\text { Only "moderate" and "severe" } \\
\text { symptoms examined here }\end{array}$ \\
\hline $\mathrm{YANG}^{\#}[24]$ & $\begin{array}{l}\text { FACIT - fatigue } \\
\text { scale }\end{array}$ & 210 & Patients with COPD & & 51 & 31 & 17 & \\
\hline $\begin{array}{l}\text { GoËRTz }^{\#, ฯ ~} \\
{[27]}\end{array}$ & $\begin{array}{l}\mathrm{CIS} \text { - subscale } \\
\text { fatigue }\end{array}$ & $\begin{array}{c}1290 \\
199\end{array}$ & $\begin{array}{l}\text { Patients with COPD } \\
\text { Non-COPD subjects }\end{array}$ & & $\begin{array}{l}25 \\
75\end{array}$ & $\begin{array}{l}26 \\
17\end{array}$ & $\begin{array}{l}49 \\
10\end{array}$ & \\
\hline $\begin{array}{l}\text { ANDERSSON } \# \\
{[29]}\end{array}$ & $\begin{array}{l}\text { FACIT - fatigue } \\
\text { scale }\end{array}$ & $\begin{array}{l}470 \\
659\end{array}$ & $\begin{array}{l}\text { Patients with COPD } \\
\text { Non-COPD subjects }\end{array}$ & $\begin{array}{l}43 \\
39\end{array}$ & & & & \\
\hline $\begin{array}{l}\text { KENTSON }{ }^{\#} \\
{[16]}\end{array}$ & $\begin{array}{l}3 \text { structured } \\
\text { questions on } \\
\text { fatigue }\end{array}$ & $\begin{array}{l}73 \\
19\end{array}$ & $\begin{array}{l}\text { Patients with COPD } \\
\text { Non-COPD subjects }\end{array}$ & $\begin{array}{l}72 \\
56\end{array}$ & & & & $\begin{array}{l}\text { Subjects reporting fatigue scores } \\
\geqslant 1 \text { were classified as "fatigue"; } \\
\text { scores of } 0 \text { as "no fatigue" }\end{array}$ \\
\hline $\begin{array}{l}\text { TheANDER } \\
{[28]}\end{array}$ & $\begin{array}{l}\text { FIS - all } \\
\text { dimensions }\end{array}$ & $\begin{array}{l}44 \\
37\end{array}$ & $\begin{array}{l}\text { Patients with COPD } \\
\text { Non-COPD subjects }\end{array}$ & $\begin{array}{l}47 \\
13\end{array}$ & & & & $\begin{array}{l}\text { Information on cut-off scores not } \\
\text { reported. COPD patients report } \uparrow \\
\text { impact of fatigue on } \\
\text { cognitive, physical and psychosocial } \\
\text { functioning in comparison to } \\
\text { controls }\end{array}$ \\
\hline $\begin{array}{l}\text { VANDEVOORDE }^{f} \\
{[20]}\end{array}$ & $\begin{array}{l}\text { One item on } \\
\text { fatigue }\end{array}$ & 68 & $\begin{array}{c}\text { All COPD } \\
\text { Patients with } \\
\text { known COPD } \\
\text { Patients with newly } \\
\text { detected COPD } \\
\text { Non-COPD subjects }\end{array}$ & $\begin{array}{l}35 \\
47\end{array}$ & & & & \\
\hline $\begin{array}{l}\text { STRANDKVIST }{ }^{\#} \\
\text { [33] }\end{array}$ & $\begin{array}{l}\text { FACIT - fatigue } \\
\text { scale }\end{array}$ & 304 & $\begin{array}{c}\text { Patients with COPD: } \\
\text { women } \\
\text { Patients with COPD: } \\
\text { men } \\
\text { Non-COPD subjects: } \\
\text { women } \\
\text { Non-COPD subjects: } \\
\text { men }\end{array}$ & $\begin{array}{l}36 \\
38 \\
28 \\
28\end{array}$ & & & & $\begin{array}{l}\text { Prevalence of clinically relevant } \\
\text { fatigue only significant between } \\
\text { male subjects with and without } \\
\text { COPD ( } p=0.016) \\
\text { Clinically relevant fatigue defined as } \\
\text { FACIT-Fatigue score of } \leqslant 43\end{array}$ \\
\hline $\begin{array}{l}\text { STRIDSMAN }{ }^{\#} \\
\text { [32] }\end{array}$ & $\begin{array}{l}\text { FACIT - fatigue } \\
\text { scale }\end{array}$ & $\begin{array}{l}367 \\
418\end{array}$ & $\begin{array}{l}\text { Patients with COPD } \\
\text { Non-COPD subjects }\end{array}$ & $\begin{array}{l}37 \\
28\end{array}$ & & & & $\begin{array}{c}\text { Clinically relevant fatigue was } \\
\text { defined as FACIT-Fatigue score of } \\
\leqslant 43\end{array}$ \\
\hline $\begin{array}{l}\text { STRIDSMAN }{ }^{\#} \\
{[31]}\end{array}$ & $\begin{array}{l}\text { FACIT - fatigue } \\
\text { scale }\end{array}$ & $\begin{array}{l}261 \\
307\end{array}$ & $\begin{array}{l}\text { Patients with COPD } \\
\text { Non-COPD subjects }\end{array}$ & $\begin{array}{l}46 \\
39\end{array}$ & & & & $\begin{array}{c}\text { Clinically significant difference } \\
\text { was identified by } 3-4 \text { unit change in } \\
\text { score }\end{array}$ \\
\hline Antoniu" [35] & $\begin{array}{l}\text { SF-36 - vitality } \\
\text { domain }\end{array}$ & 12 & Patients with COPD & 60 & & & & $\begin{array}{l}\text { Clinically significant fatigue } \\
\text { was defined as score } \leqslant 50\end{array}$ \\
\hline $\mathrm{GIFT}^{\#}[21]$ & $\begin{array}{l}\text { SF-36 - vitality } \\
\text { domain }\end{array}$ & 104 & Patients with COPD & 58 & & & & $\begin{array}{l}\text { Number calculated by } \% \text { responders } \\
\text { who gave a positive answer to } \\
\text { question about feeling a lack of } \\
\text { energy during the past week }\end{array}$ \\
\hline
\end{tabular}




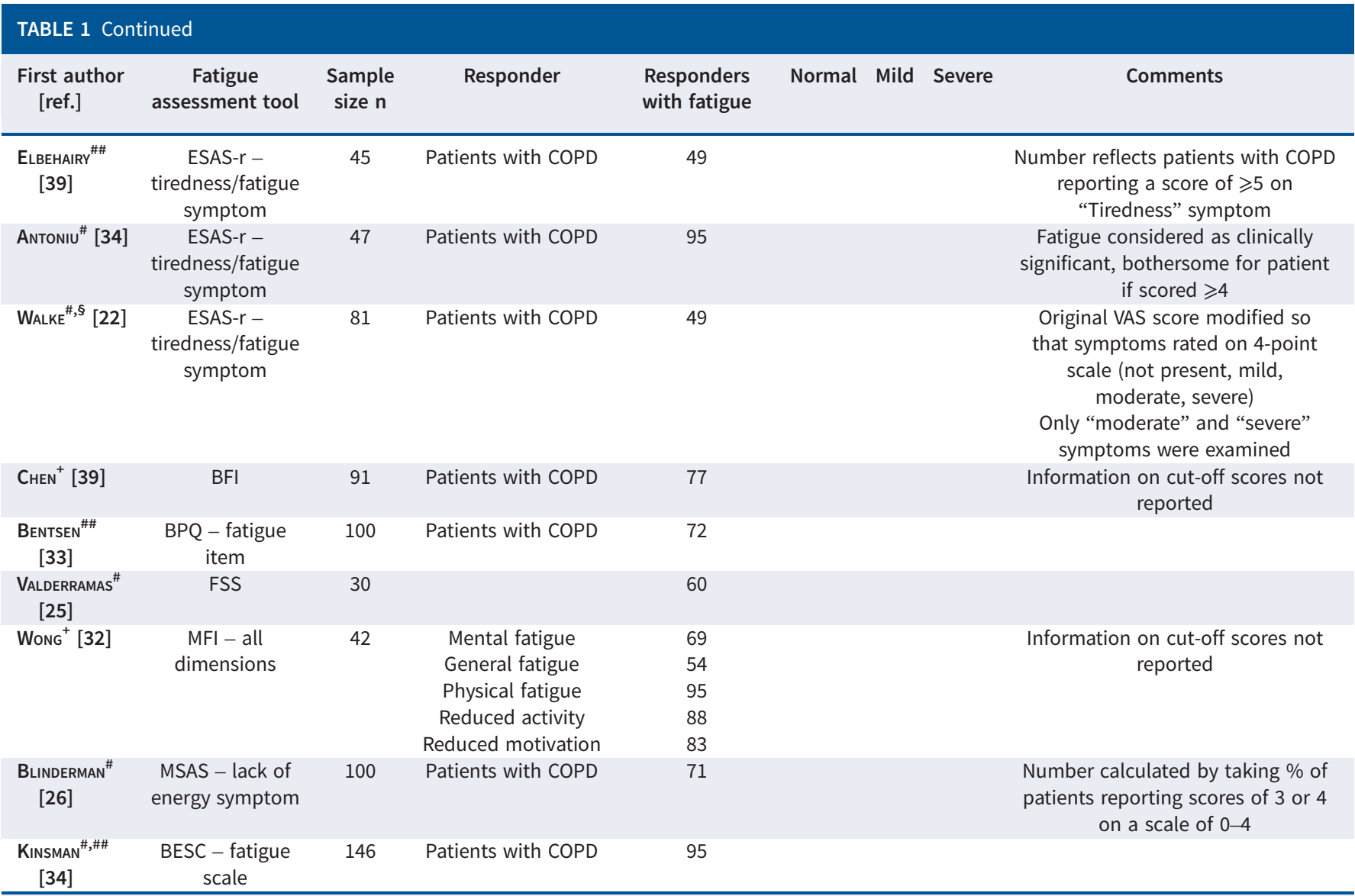

Data are presented as \%, unless otherwise stated. CIS: Checklist Individual Strength; SF-36: 36-item Short-Form Health Survey; ESAS: Edmonton Symptom Assessment Scale; VAS: visual analogue score; FACIT: Functional Assessment of Chronic Illness Therapy - Fatigue Scale; FIS: Fatigue Impact Scale; BFI: Brief Fatigue Inventory; BPQ: Breathing Problem Questionnaire; FSS: Fatigue Severity Scale; MFI: Multidimensional Fatigue Inventory; MSAS: Memorial Symptom Assessment Scale; BESC: Bronchitis-Emphysema Symptom Checklist. \#: secondary care population; `: data partially obtained from the same set of data; ${ }^{+}$: pulmonary rehabilitation population; ${ }^{\S}$ : data obtained from the same set of data; ${ }^{f}$ : primary care population; \#\#: tertiary care population.

Of the studies that reported significant associations, StRIDSMAn et al. [31] adjusted for sex, smoking habits, any respiratory symptom, anxiety/depression, heart disease and health care contacts (unadjusted OR 1.04, 95\% CI 1.02-1.07, p<0.05; adjusted OR 0.02, 95\% CI 0.98-1.05, p>0.05) (online supplementary table 3).

Sex

Ten papers explored the association or group difference between sex and fatigue [12, 27, 31, 44-46, 48, 51-53] (online supplementary table 3 and figure 2). Results regarding differences in fatigue levels between men and women are conflicting. Six of the 10 studies described a nonsignificant association or between-group difference [31, 44, 46, 48, 51, 52], whereas the other four reported a poor but significant correlation $(r=0.11, p<0.05)$ [27] or a group difference $(\mathrm{p}<0.05)[12,45,53]$. The studies that reported a difference observed that women with COPD experience more severe fatigue compared with male subjects with COPD [12, 27, 45, 53]. One study controlled the association between fatigue and the factor "sex" for confounders [38], and reported a nonsignificant association (online supplementary table 3).

\section{Socioeconomic status}

No associations were found between work status, economic status and fatigue [27, 44, 52]. Of the five studies assessing the association between the level of education and fatigue [27, 44, 45, 51, 52], two studies indicated that lower educated patients with COPD experience significantly more fatigue than higher educated patients [45, 52] (online supplementary table 3 and figure 2). 


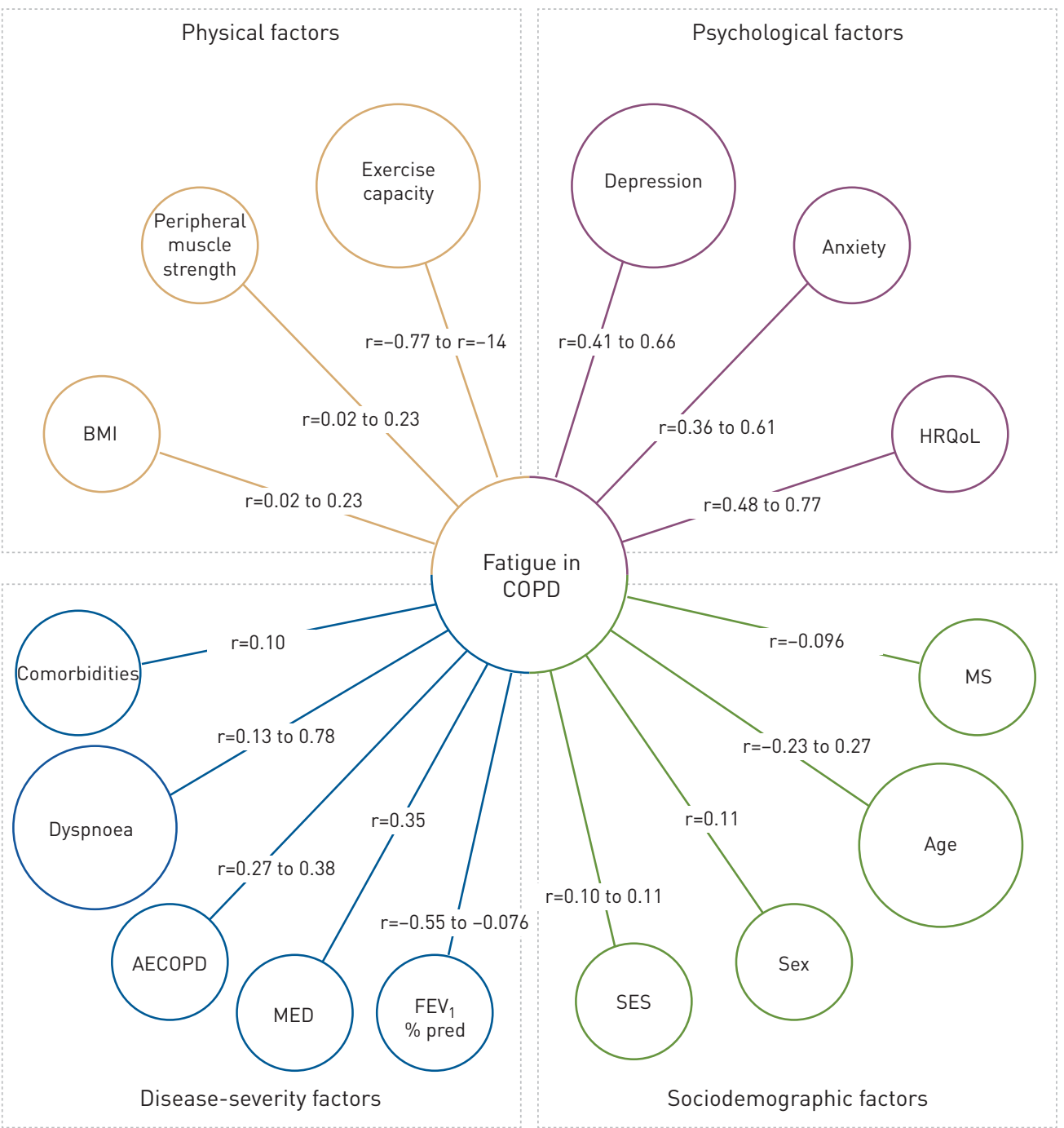

FIGURE 2 Factors associated with fatigue in COPD. Balloon sizes reflect numbers of studies reported. Increased line width indicates higher mean scores of correlation coefficients $(r)$ found. For each factor, correlation coefficient ranges from different studies are shown. For the categorical variable "sex": male $=0$, female $=1$. Other categorical variables (e.g. SES, marital status) not specified. AECOPD: acute exacerbations of COPD; BMI: body mass index; $\mathrm{FEV}_{1}$ : forced expiratory volume in $1 \mathrm{~s}$; HRQoL: health-related quality of life; MED: number of medications; MS: marital status; SES: socioeconomic status.

Marital status

Three papers examined fatigue in association with marital status [27, 44, 52] (online supplementary table 3 and figure 2). One paper reported a poor, but significant relationship between fatigue and marital status $(\mathrm{r}=-0.096)$, indicating that patients with a partner were less fatigued than patients without a partner [27]. KARAKURT et al. [52] found that widowed individuals experienced more severe fatigue, compared with married and unmarried individuals. In the study by Mollaoglu et al. [44], a statistically significant difference was found between married and single individuals on fatigue scores $(\mathrm{p}<0.05)$, indicating that married patients experienced more fatigue than single patients. Whether widowed individuals were included in the group of single individuals was not described in that paper.

\section{Disease-severity factors associated with fatigue}

Degree of airflow limitation

In total, 20 studies investigated the association between fatigue and the degree of airflow limitation $\left(\mathrm{FEV}_{1}\right.$ $\%$ predicted) $[6,8,11,12,14-16,25,27,36,41-43,49,51,54-58]$ (online supplementary table 4 and figure 2$)$. The majority of the studies $(n=17)$ reported a poor or nonexisting association $(r<0.30)[6,11,12$, 
14, 16, 27, 36, 41-43, 49, 51, 54-58], two reported a moderate correlation ( $r=-0.50$ and $r=-0.30)$ [15, 25], and only one study found a strong association with the degree of airflow limitation $(r=-0.55)$ [8]. Of those describing a moderate-to-strong association, all reported a significant, negative relationship between fatigue and the $\mathrm{FEV}_{1} \%$ pred. Additionally, several studies controlled the association between fatigue and the factor "FEV 1 \% predicted" for confounders [13, 31, 38, 55]. Of the studies that reported a significant association, STRIDSMAn et al. [31] adjusted for age, sex, smoking habits, any respiratory symptoms, anxiety/ depression, heart disease, and health care contacts (unadjusted OR 0.97, 95\% CI 0.96-0.98, p<0.05; adjusted OR 0.98, 95\% CI 0.96-1.00, p<0.05) (online supplementary table 4).

Dyspnoea

The link between dyspnoea and fatigue has been studied extensively $(\mathrm{n}=25)[6,11,12,16,21,25,27,35$, 36, 41, 44, 45, 47-51, 54, 59-64] (online supplementary table 4 and figure 2). Two studies reported significant but poor relationships between dyspnoea and fatigue $(r=0.13$ and $r=0.26)$ [41, 63], nine studies reported moderate significant associations ( $\mathrm{r}=0.31$ to 0.48$)[6,11,27,48,49,59,61,62,64]$, and nine studies strong significant associations ( $\mathrm{r}=0.51$ to 0.78 ) $[12,21,25,36,47,50,51,54,60]$. Four studies explored the differences between fatigue severity groups and dyspnoea [16, 35, 44, 45] or between levels of dyspnoea severity and fatigue [45]; these studies all illustrated that more severe dyspnoea is statistically significant related to higher fatigue levels $(\mathrm{p}<0.05)$. Furthermore, the study by Woo et al. [50] adjusted the association between dyspnoea and fatigue for $\mathrm{FEV}_{1}$, and reported a significant association $(\mathrm{p}<0.001)$.

\section{Number of exacerbations}

Eight papers examined the association between the number of exacerbations and fatigue [11, 12, 27, 38, $43,45,65,66$ ] (online supplementary table 4 and figure 2). In some studies exacerbations were commonly quantified as rate per year, whereas other studies reported exacerbation rates prior to 6 months, prior to 4 weeks, or at the beginning of the study. Among these studies, two studies reported nonsignificant relationships $(p>0.05)$ [38, 43]. From the studies that reported significant relationships, six studies presented significant, but poor correlations $(r<0.30)[11,12,27,65,66]$ and one a moderate correlation $(\mathrm{r}=0.38)$ [45]. All studies found that patients who had more exacerbations were significantly more fatigued than patients with no or less exacerbations. Moreover, one study controlled the correlation between fatigue and "number of exacerbations" for confounders [38], and reported a nonsignificant association (online supplementary table 4).

\section{Number of comorbidities}

Six studies provided information on the presence or number of comorbidities in association with fatigue [11, 27, 35, 37, 38, 66] (online supplementary table 4 and figure 2). One study described a nonsignificant association [37], while another study reported a poor but significant correlation between presence of comorbidities and fatigue $(\mathrm{r}=0.10)$ [27]. JonEs et al. [66] reported a significant difference between fatigue scores of patients with no comorbidities and patients with more than three comorbidities, but also between the patients with one to two comorbidities and patients with more than three comorbidities. BALTZAN et al. [35] compared patients with low and high fatigue levels, and found that comorbid diseases (coronary artery disease, arrhythmia, current heart failure, hypertension, peripheral vascular, depression, insomnia, obstructive sleep apnoea, history of cancer, musculoskeletal disease) associated with fatigue were equally distributed between the high and low fatigue groups ( $\mathrm{p}>0.05)$. BAGHAI-RAvARY et al. [11] observed that patients with a history of ischemic heart disease had higher fatigue scores compared with other patients $(p<0.05)$, although this association was no longer significant in following adjustment for other related factors $(\mathrm{p}>0.05)$. Furthermore, one study controlled the correlation between fatigue and the "number of comorbidities" for confounders, and reported a non-significant association [38] (online supplementary table 4).

\section{Medication}

Three papers reported information on medication use in relation to fatigue in patients with COPD [27, 48, 67] (online supplementary table 4 and figure 2). Each of these three studies used a different approach to report medication use in association to fatigue. GoËrTz et al. [27] reported a statistically significant association between the number of medications and fatigue. Patients with a higher degree of fatigue used more medications than patients with mild or normal fatigue $(\mathrm{r}=0.35, \mathrm{p}<0.05)$. REIshTEIN et al. [48] reported no association between fatigue and different medications used.

\section{Physical factors associated with fatigue}

Exercise capacity and peripheral muscle strength

To date, the relationship between exercise capacity and fatigue has been studied more extensively $(n=15)$ compared with the association between peripheral muscle strength and fatigue $(n=3)$ (online supplementary 
table 5 and figure 2). Of the 15 studies investigating the association of fatigue with exercise capacity, five did not find significant associations [14, 37, 43, 56, 57], four found significant but weak associations $(\mathrm{r}=-0.29$ to $\mathrm{r}=-0.14)[16,41,54,59]$, three observed significant moderate associations ( $\mathrm{r}=-0.35$ to $\mathrm{r}=-0.30$ ) [49, 55, 62], and three studies found significant strong relationships ( $\mathrm{r}=-0.77$ to $\mathrm{r}=-0.55$ ) $[13,15,25]$. Exercise capacity was mostly studied with the 6-min walk test (6 MWT; $n=12$ ), followed by the symptom-limited cycle exercise test $(n=2)$, and the incremental shuttle walk test (ISWT; $n=1)$. The majority of the papers indicated that a lower exercise capacity was related to more fatigue. CALIK-KutuKcu et al. [60] found a strong and negative correlation between fatigue (total Fatigue Severity Scale (FSS) score) and upper extremity muscle force (shoulder abductor $\mathrm{r}=-0.72$, shoulder flexor $\mathrm{r}=-0.78$; $\mathrm{p}=0.001$, respectively), whereas BREUKINK et al. [14] observed moderate-to-strong relations between the physical dimension of the MFI-20 and the muscle torque of the biceps and triceps ( $r=-0.61$ to $r=-0.45, p \leqslant 0.05$, respectively). In addition to the upper extremity muscles, Breukink et al. [14] also found significant, moderate-to-strong correlations between fatigue, the muscle torque of the left hamstrings $(r=-0.49)$ and the muscle torque of the left and right quadriceps ( $\mathrm{r}=-0.49$ and $\mathrm{r}=-0.54)$. STRANDKVIST et al. [32] found that among men with COPD, but not women, hand grip strength was negatively associated with fatigue (B 0.249, 95\% CI 0.131-0.367), and this association was independent of physical activity (B 0.190, 95\% CI 0.061-0.319). Two studies reported on the use of confounders in the reported association between "exercise capacity" and fatigue [32, 55]. STRANDKVIST et al. [32] adjusted for smoking habits, age and height $(\mathrm{p}<0.05)$, whereas ToDT et al. [55] corrected for sex $(\mathrm{p}<0.05)$ (online supplementary table 5).

\section{Body composition}

Three studies reported a relationship between body mass index (BMI) and fatigue [27, 43, 53] (online supplementary table 5 and figure 2). No studies investigated the association of fatigue with waist circumference, nor with body composition. Of the studies examining the relationship between BMI and fatigue, two out of three studies did not find a significant association between fatigue and BMI ( $\mathrm{p}>0.05)$ [27, 43]. Only СRоскетт et al. [53] reported significant but poor associations, for both male and female patients with COPD (male: $\mathrm{r}=0.23$, female: $\mathrm{r}=-0.02$ ). Furthermore, BALTZAN et al [35]. reported a nonsignificant difference in BMI between patients with high or low fatigue scores.

\section{Psychological factors associated with fatigue Depression}

Depression in association with fatigue was investigated in 18 out of 196 papers [11, 12, 15, 16, 31, 35, 37, 38, 45, 49, 51, 52, 54, 62, 68-71] (online supplementary table 6 and figure 2). From these 18 studies, only one presented a nonsignificant relationship between fatigue and depression [37], six studies described significant moderate correlations ( $\mathrm{r}=0.30$ to $\mathrm{r}=0.50, \mathrm{p}<0.05)$ [12, 15, 49, 52, 62, 68], and eight studies significant strong correlations ( $\mathrm{r}=0.53$ to $\mathrm{r}=0.66, \mathrm{p}<0.05$ ) $[11,12,16,49,51,54,69-71]$. One study [68] described a moderate significant correlation $(\mathrm{r}=0.382$ ) between depressive mood and fatigue, but the results of a multiple regression analysis showed no significant relationship. BALTZAN et al. [35] divided COPD patients into high and low fatigue groups. They reported that patients in the high fatigue group showed significantly higher depression scores than those in the low fatigue group. Furthermore, this study showed that a diagnosis of depression in patients in the high fatigue group was more common than in patients in the low fatigue group [35]. Additionally, two studies controlled the association between fatigue and the factor “depressive moods” for confounders. Only BENTSEN et al. [38] found a significant association after adjusting for age, gender, lung function, comorbidity and exacerbations (OR 7.13, 95\% CI 1.87-27.22, $\mathrm{p}=0.004$ ) (online supplementary table 6).

Anxiety

The association between anxiety and fatigue is described in 12 of 196 studies [12, 16, 31, 37, 38, 41, 45, 51, 52, 54, 68, 71] (online supplementary table 6 and figure 2). Of these 12 studies, only one reported a nonsignificant relation between anxiety and fatigue, one study reported a poor association ( $\mathrm{r}=0.23)$ [37], six studies described significant moderate correlations ( $\mathrm{r}=0.36$ to 0.50 ) [12, 15, 41, 49, 52, 62, 68], and two studies found significant strong correlations $(\mathrm{r}=0.59$ to $\mathrm{r}=0.61)[12,54]$. PARReIRA et al. [68] reported a moderate significant correlation between anxiety and fatigue $(\mathrm{r}=0.36)$, but results of a regression analysis showed no significant relationship between anxiety and fatigue $(\mathrm{B}=0.730, \mathrm{~F}=0.796$; $\mathrm{p}=0.622)$. Moreover, two studies controlled the correlation between fatigue and the factor "anxious moods" for confounders [31, 38], and no significant results were reported in these studies (online supplementary table 6).

Health-related quality of life

Nine studies examined the association between fatigue and health-related quality of life (HRQoL) [16, 27, 49, 54, 56, 62, 72-74] (online supplementary table 6 and figure 2). One out of nine studies reported a nonsignificant association ( $p>0.05$ ) between fatigue and HRQoL [72]. Of the eight studies reporting a 
significant relationship, one study described a moderate correlation $(\mathrm{r}=-0.48)$ [62] and seven a strong relationship ( $r=-0.56$ to $r=0.77$ ) $[16,27,49,54,56,73,74]$, in which patients with more severe fatigue reported worse HRQoL.

\section{Assessment of fatigue}

In total, 28 different assessment tools have been used to measure fatigue in the 196 included studies. Additionally, 11 studies reported using structured questions on the frequency, duration and severity of fatigue. Results show that the Chronic Respiratory Disease Questionnaire or Chronic Respiratory Questionnaire (CRDQ/CRQ) is the most frequently used questionnaire to assess fatigue in patients with COPD (39\%), followed by the FSS (7\%) and the Functional Assessment of Chronic Illness Therapy (FACIT) (7\%). The characteristics of the 13 most commonly used questionnaires [21, 35, 47, 75-94] are summarised in table 2. In most questionnaires higher scores represent more severe fatigue: FSS, Multidimensional Fatigue Index (MFI-20), Edmonton Symptom Assessment System (ESAS), Profile of Mood States (POMS), Checklist Individual Strength (CIS-Fatigue), COPD and Asthma Fatigue Scale (CAFS), Manchester COPD Fatigue Scale (MCFS), Memorial Symptom Assessment Scale (MSAS), Brief Fatigue Inventory (BFI), and Visual Analogue Scale for Fatigue (VAS-F)/Lee Fatigue Scale (LFS). In contrast, for the Chronic Respiratory (Disease) Questionnaire (CRDQ/CRQ), 36-item Short-Form Health Survey (SF-36)/Medical Outcomes Study 36-Item Short-Form Health Survey (MOS-36) and FACIT questionnaires, higher scores indicate less severe fatigue. Of the 13 questionnaires described in table 2, only three instruments described a cut-off score indicating abnormal or moderate/severe fatigue (CIS-Fatigue, FACIT and ESAS) [75-81]. However, only one instrument (CIS-Fatigue) [75-77] validated these cut-off scores using different norm groups, including healthy subjects and different patient samples.

\section{Discussion}

This systematic review provides insights into the prevalence of fatigue in patients with COPD and factors that are associated with fatigue in COPD. Results underline the complexity of fatigue in COPD; multiple physical and psychological factors appear to be associated with fatigue. Nevertheless, results on factors such as age, gender, SES, degree of airflow limitation, exercise capacity and body composition were not conclusive and were sometimes contradictory. Only results on dyspnoea, depression, anxiety, quality of life and peripheral muscle strength were conclusive and showed moderate-to-strong associations with fatigue.

The results of this review show that the prevalence of fatigue in COPD varied from 17-95\%. However, these prevalence rates greatly depend on the measurement method used, the setting of the study, and in particular, the lack of validated cut-off scores to discriminate between normal and abnormal (severe) fatigue. Additionally, these cut-off scores should be validated both in patient samples as well as in healthy controls, since normal fatigue is also a natural phenomenon in healthy subjects. In addition to the assessment method, the characteristics of the different study populations also contributed to the difficulty of interpreting the differences in prevalence rates between the studies. For example, the lowest prevalence rate $(17 \%)$ was observed in a study by YANG et al. [24], who studied fatigue in a sample of 210 patients with COPD hospitalised for acute exacerbations of chronic obstructive pulmonary disease (AECOPD) during the moment of inclusion. In contrast, the highest prevalence of fatigue (95\%) was reported by Kinsman et al. [40], who examined fatigue in patients during hospital stays in which patients were asked about occurrence of fatigue during breathing difficulties. Importantly, this $17 \%$ only reflected patients who experienced severe fatigue, whereas the study in which $95 \%$ of patients experienced fatigue did not differentiate between normal, mild or moderate, and severe fatigue, making it difficult to compare the studies. In addition, fatigue in COPD is mostly examined in a secondary and tertiary care settings.

The majority of studies on the differences between patients with COPD and non-COPD controls show that fatigue is more prevalent in patients with COPD than in non-COPD controls [16, 20, 27, 28, 30, 31]. Nevertheless, the sample sizes of the non-COPD controls in most of these studies were rather small $(n=34$ to 95). In a population-based study by ANDERSSON et al. [29], a larger non-COPD control group was included (470 patients with COPD and 659 non-COPD controls). However, this study reported a nonsignificant difference in fatigue scores between patients with COPD and non-COPD controls. In contrast, a larger (1290 patients with COPD and 199 non-COPD controls), more recent study by GoËRTZ et al. [27] showed a significant difference in fatigue severity between these two groups: severe fatigue is more prevalent in patients with COPD compared with subjects without COPD. These contradictions in results show again that is it difficult to compare studies which have different methodologies and study populations.

Taken together, due the heterogeneity of measurement methods, settings of the studies, and lack of validated cut-off scores that can discriminate between normal and abnormal fatigue in the majority of 
TABLE 2 Characteristics of the fatigue assessment tools/subscales measuring fatigue

\begin{tabular}{|c|c|c|c|c|c|c|c|c|c|}
\hline Assessment tool & Purpose & Items & $\begin{array}{l}\text { Fatigue } \\
\text { subscale }\end{array}$ & Scale type & Fatigue scale cut-off score & Scoring & $\begin{array}{l}\text { Internal } \\
\text { consistency }\end{array}$ & $\begin{array}{l}\text { Test- } \\
\text { retest } \\
\text { reliability }\end{array}$ & $\begin{array}{c}\text { Studies } \\
\text { questionnaire } \\
\text { used } n\end{array}$ \\
\hline CRDQ/CRQ [82, 83] & Impact & 5 & 1 & 7-point Likert & MCID 0.5 per item & $\begin{array}{l}\text { Higher score, } \\
\text { lower fatigue }\end{array}$ & $0.51-0.83$ & $0.90-0.93$ & 77 \\
\hline FSS $[84,85]$ & Impact & 9 & 1 & 7-point Likert & 4 & $\begin{array}{l}\text { Higher score, } \\
\text { higher fatigue }\end{array}$ & 0.88 & 0.84 & 14 \\
\hline $\begin{array}{l}\text { SF-36/MOS-36 [21, } \\
\quad 35,80,86]\end{array}$ & Severity & 4 & 1 & 1-6-point Likert & $\begin{array}{l}\text { Participants have high fatigue if scores } \\
<2 \text { sD from published mean } \\
\text { age-adjusted normal vitality scores for } \\
\text { general Canadian population }\end{array}$ & $\begin{array}{l}\text { Higher score, } \\
\text { lower fatigue }\end{array}$ & $0.71-0.92$ & 0.62 & 14 \\
\hline FACIT $[24,79,85]$ & Severity/impact & 13 & 1 & 5-point Likert & $\begin{array}{l}\text { Mild: } 24-36 \\
\text { Moderate: } 12-23 \\
\text { Severe: } 0-11\end{array}$ & $\begin{array}{l}\text { Higher score, } \\
\text { lower fatigue }\end{array}$ & 0.93 & 0.90 & 13 \\
\hline VAS-F/LFS $[87,88]$ & Severity & 13 & 1 & Visual analogue & $\begin{array}{l}\text { Fatigued when score is above } 50 \% \text { of } \\
\qquad 100 \%\end{array}$ & $\begin{array}{l}\text { Higher score, } \\
\text { higher fatigue }\end{array}$ & $0.91-0.96$ & $\begin{array}{c}\text { Not } \\
\text { described }\end{array}$ & 10 \\
\hline MFI-20 $[85,89,90]$ & $\begin{array}{l}\text { Phenomenology/ } \\
\text { severity/impact }\end{array}$ & 20 & 5 & 7-point Likert & $\geqslant 13$ (severe fatigue) & $\begin{array}{l}\text { Higher score, } \\
\text { higher fatigue }\end{array}$ & 0.84 & $\begin{array}{c}\text { Not } \\
\text { described }\end{array}$ & 10 \\
\hline CAFS [91] & Severity/impact & 12 & 1 & 5-point Likert & Not described & $\begin{array}{l}\text { Higher score, } \\
\text { higher fatigue }\end{array}$ & 0.95 & 0.82 & 5 \\
\hline MSAS [92] & Severity & 3 & 1 & 5-point Likert & Not described & $\begin{array}{l}\text { Higher score, } \\
\text { higher fatigue }\end{array}$ & $0.76-0.87$ & $0.40-0.94$ & 5 \\
\hline BFI [93] & Severity & 9 & 1 & 11-point Likert & $\geqslant 7$ & $\begin{array}{l}\text { Higher score, } \\
\text { higher fatigue }\end{array}$ & 0.96 & $\begin{array}{c}\text { Not } \\
\text { described }\end{array}$ & 4 \\
\hline ESAS $[80,81]$ & Severity/impact & 1 & 1 & 11-point Likert & $\begin{array}{l}\text { 3-4 (moderate) } \\
\text { 5-7 (severe) }\end{array}$ & $\begin{array}{l}\text { Higher score, } \\
\text { higher fatigue }\end{array}$ & 0.79 & $0.45-0.86$ & 4 \\
\hline POMS $[85,94]$ & Severity & 7 & 1 & 5-point Likert & Not described & $\begin{array}{l}\text { Higher score, } \\
\text { higher fatigue }\end{array}$ & 0.80 & $\begin{array}{c}\text { Not } \\
\text { described }\end{array}$ & 4 \\
\hline MCFS [47] & Severity & 27 & 3 & 5-point Likert & Not described & $\begin{array}{l}\text { Higher score, } \\
\text { higher fatigue }\end{array}$ & 0.97 & 0.97 & 3 \\
\hline $\begin{array}{l}\text { CIS Subjective } \\
\text { Fatigue subscale } \\
\text { [75-77] }\end{array}$ & $\begin{array}{l}\text { Phenomenology/ } \\
\text { severity }\end{array}$ & 8 & 1 & 7-point Likert & $\begin{array}{c}<27 \text { (normal) } \\
\geqslant 27 \text { (moderate) } \\
\geqslant 35 \text { (severe) }\end{array}$ & $\begin{array}{l}\text { Higher score, } \\
\text { higher fatigue }\end{array}$ & 0.90 & $\begin{array}{c}\text { Not } \\
\text { described }\end{array}$ & 3 \\
\hline
\end{tabular}

CRDQ/CRQ: Chronic Respiratory (Disease) Questionnaire; FSS: Fatigue Severity Scale; SF-36: Short-Form-36; MOS-36: Medical Outcomes Study 36-Item Short-Form Health Survey; FACIT: Functional Assessment of Chronic Illness Therapy; VAS-F: Visual Analogue Scale for Fatigue; LFS: Lee Fatigue Scale; MFI-20: Multi-dimensional fatigue index; CAFS: COPD and Asthma Fatigue Scale; MSAS: Memorial Symptom Assessment Scale; BFI: Brief Fatigue Inventory; ESAS: Edmonton Symptom Assessment System; POMS: Profile Of Mood States; MCFS: Manchester COPD Fatigue Scale; CIS: Checklist Individual Strength; MCID: minimal clinically important difference." : additional searches were performed. 
studies, it is difficult to draw solid conclusions on the prevalence range of fatigue in subjects with COPD and non-COPD subjects. In future studies on the prevalence of fatigue in patients with COPD, the emphasis should lie on the comparison of the prevalence rates between patients with COPD and healthy controls. Additionally, this systematic review highlights the use of fatigue questionnaires with well validated cut-off scores.

\section{Is fatigue the result of lung function impairment?}

Fatigue has been long considered to be a direct result of airflow limitation. However, the results of current studies showed contradictory results, with the majority of studies showing nonsignificant associations [6, $11,12,14,16,27,36,41-43,49,51,54-58]$. Moreover, in studies that found associations, sample sizes were small ( $n=22$ to 52 participants) [8, 15, 25]. A study with a larger sample size ( $n=1290)$ reported a significant, but poor association [27]. Moreover, a longitudinal study showed that even though the degree of airflow limitation remained stable during a 4-year follow-up, the proportion of patients with severe fatigue doubled [6]. Altogether, this suggests that the degree of airflow limitation is not a major, let alone the primary, underlying cause of fatigue in patients with COPD. This means that the causes of fatigue should also be sought in other physical, psychological and behavioural factors.

\section{Which factors are associated with fatigue in COPD?}

There were no clear bivariate associations identified between fatigue and demographic factors, indicating that other factors, e.g. physical or psychological factors, could be associated with fatigue.

Results on the associations between comorbid conditions and fatigue appear to be conflicting [11, 27, 35, 37, 38, 66]. Moreover, the interpretation of the associations between fatigue and comorbid conditions is challenging, since studies use different approaches to study comorbidities; some describe the presence of certain comorbidities, whereas others only report the number of comorbidities. In addition, diagnosis of some comorbidities may easily be missed, since some studies used standardised lists, such as the Charlson Comorbidity Index, which do not include all conditions. These limitations could explain why the results on the associations between comorbid conditions and fatigue in COPD were conflicting.

The current literature also does not provide unambiguous answers on physical factors that are associated with fatigue. The results of this systematic review show that a lower exercise capacity and decreased muscle strength are associated with more fatigue. But again, the heterogeneity in sample sizes and outcome measures (e.g. exercise capacity tests, studied muscle groups and fatigue scales) complicated the comparison of the results between studies [6, 13-15, 38, 41, 47, 51, 53, 54, 57, 60, 61, 73, 79, 81].

The most convincing evidence for factors related to fatigue was found for dyspnoea, depression, anxiety and HRQoL. This is in line with a recent study that used multiple regression and found that dyspnoea was responsible for the largest unique contribution of explained variance in fatigue [27]. Nevertheless, PETERS et al. [6] found that fatigue and dyspnoea, although interrelated, are distinct phenomena.

Most reviewed studies reported moderate-to-strong associations between fatigue and depression, as well as between fatigue and anxiety [6, 12, 15, 16, 41, 42, 47, 48, 51, 67-71]. Moreover, findings of multivariate analyses showed that depressive moods, dyspnoea and sleep problems accounted for $42 \%$ of the variance in fatigue [12]. Furthermore, this study demonstrated that almost all patients with clinically relevant depressive and anxiety symptoms experienced fatigue. However, to date the causal direction of these associations is unclear and needs to be further investigated.

\section{Strengths and limitations}

The current review has some strengths and limitations. A strength of this review is that it was carried out using a replicable methodology, with screening and data extraction being conducted by two independent researchers in order to reduce bias. Moreover, this review covers a broad range of topics that are important in the field of fatigue in patients with COPD. Nevertheless, this literature review also has some limitations. Due the variety of the different tools used to measure fatigue in different studies, no meta-analyses could be carried out. Additionally, only papers that were published in English, Dutch or German were included in this review. This may have led to the exclusion of relevant studies on fatigue in COPD patients that were published in other languages. Furthermore, no quality assessment was carried out on included studies in this paper. At last, information about the association between the factors and fatigue were based on cross-sectional data. This does not allow conclusions concerning the direction of causation between associations found. 


\section{Implications for research}

Many instruments have been used to measure fatigue in COPD. Especially with respect to determining the prevalence of clinically relevant levels of fatigue, a questionnaire should be used that distinguishes between normal fatigue and abnormal fatigue. This is crucial as fatigue is a normal phenomenon in healthy people as well. Hence, abnormality cannot be defined as the mere presence of fatigue. To our knowledge, the CIS-Fatigue is the only instrument that uses a cut-off to discriminate between normal and abnormal severe fatigue. This cut-off was validated in different patient samples and healthy subjects [75-77]. In addition, some instruments measure fatigue based on frequency ratings. Although this type of assessment provides valuable information, a fatigue severity measure should always be included.

Many factors have been found to be associated with fatigue in COPD. However, these findings were derived from many different studies, using different assessment methods and different samples. It is therefore unclear which factors provide a unique contribution to fatigue. In addition, it is unknown whether these associations represent causal relationships, and if so, what the direction of the causation is. Moreover, an association between a specific factor and fatigue may also indicate that both are the result of another underlying mechanism. In that case the association between this factor and fatigue does not represent a causal relationship.

Future research should include all factors that have been consistently shown to be associated with fatigue in different studies into one integrated (multivariate) analysis, to evaluate the unique contribution of each factor in explaining fatigue. In addition, longitudinal studies are needed to identify whether associations between specific factors and fatigue represent a causal relationship or whether these factors both are merely results that are based on the same underlying process. Currently, a large longitudinal study (FAntasTIGUE) is ongoing to fill this gap [95].

\section{Implications for clinical practice}

Even though much is unclear regarding knowledge on factors that perpetuate fatigue as described above, the results suggest that many factors may contribute to abnormal severe fatigue in patients with COPD. To be able to tailor treatment to individual patients, a detailed assessment evaluating all possible factors is a pre-requisite. Therefore, screening for fatigue and exploring underlying causes in patients with COPD should be a routine part of usual COPD care.

\section{Conclusion}

The findings of this review show that there is an high variability in the measurement methodologies of fatigue, and consequently in its prevalence. This high variability and ambivalence makes it difficult to interpret and draw solid conclusions on the prevalence rates. Nevertheless, the general picture is that fatigue is an important symptom in COPD that warrants more attention in research and clinical practice. Fatigue in COPD may be caused by many different factors including physical, psychological and behavioural, but which of these factors provide a unique contribution is still unknown. Furthermore, the contradictions found in the literature on the majority of factors make the expression of the statistical differences to clinical importance very challenging. As fatigue in the literature is found to be an important symptom in patients with COPD, there is an urgent and unmet need for a better understanding of fatigue and its multicausality. A better understanding of the factors that cause and perpetuate fatigue in patients with COPD will lead to the development of fatigue-reducing interventions. These interventions most likely require an individualised modular approach.

Clinical trial registration: This study is registered at www.crd.york.ac.uk/prospero with identifier 42017068136.

Provenance: Submitted article, peer reviewed

Support statement: This project is supported by grant 4.1.16.085 of Lung Foundation Netherlands (Leusden, The Netherlands), AstraZeneca Netherlands, Boehringer Ingelheim Netherlands and Stichting Astma Bestrijding (Amsterdam, The Netherlands). Funding information for this article has been deposited with the Crossref Funder Registry.

Conflict of interest: Z. Ebadi has nothing to disclose. M.J. Goërtz has nothing to disclose. M. Van Herck has nothing to disclose. D.A.J. Janssen reports personal fees from Novartis, Boehringer Ingelheim and AstraZeneca, outside the submitted work. M.A. Spruit reports grants from Netherlands Lung Foundation, Stichting Astma Bestrijding, Boehringer Ingelheim and AstraZeneca, during the conduct of the study; and personal fees from Boehringer Ingelheim and AstraZeneca, outside the submitted work. C. Burtin has nothing to disclose. M.S.Y. Thong has 
nothing to disclose. J. Muris has nothing to disclose. J. Otker has nothing to disclose. M. Looijmans has nothing to disclose. C. Vlasblom has nothing to disclose. J. Bastiaansen has nothing to disclose. J. Prins has nothing to disclose. E.F.M. Wouters has nothing to disclose. J.H. Vercoulen has nothing to disclose. J.B. Peters has nothing to disclose.

\section{References}

1 Singh D, Agusti A, Anzueto A, et al. Global strategy for the diagnosis, management, and prevention of chronic obstructive lung disease: the GOLD science committee report 2019. Eur Respir J 2019; 53: 1900164.

2 Janson-Bjerklie S, Carrieri VK, Hudes M. The sensations of pulmonary dyspnea. Nurs Res 1986; 35: 154-159.

3 Small SP, Lamb M. Measurement of fatigue in chronic obstructive pulmonary disease and in asthma. Int $J$ Nurs Stud 2000; 37: 127-133.

4 Ream E, Richardson A. Fatigue in patients with cancer and chronic obstructive airways disease: a phenomenological enquiry. Int J Nurs Stud 1997; 34: 44-53.

5 Stridsman C, Skar L, Hedman L, et al. Fatigue affects health status and predicts mortality among subjects with COPD: report from the population-based OLIN COPD study. COPD 2015; 12: 199-206.

6 Peters JB, Heijdra YF, Daudey L, et al. Course of normal and abnormal fatigue in patients with chronic obstructive pulmonary disease, and its relationship with domains of health status. Patient Educ Couns 2011; 85: 281-285

7 Spruit MA, Vercoulen JH, Sprangers MAG, et al. Fatigue in COPD: an important yet ignored symptom. Lancet Respir Med 2017; 5: 542-544.

8 Inal-Ince D, Savci S, Saglam M, et al. Fatigue and multidimensional disease severity in chronic obstructive pulmonary disease. Multidiscip Respir Med 2010; 5: 162-167.

9 Lewko A, Bidgood PL, Garrod R. Evaluation of psychological and physiological predictors of fatigue in patients with COPD. BMC Pulm Med 2009; 9: 47.

10 Theander K, Jakobsson P, Torstensson $\mathrm{O}$, et al. Severity of fatigue is related to functional limitation and health in patients with chronic obstructive pulmonary disease. Int J Nurs Pract 2008; 14: 455-462.

11 Baghai-Ravary R, Quint JK, Goldring JJ, et al. Determinants and impact of fatigue in patients with chronic obstructive pulmonary disease. Respir Med 2009; 103: 216-223.

12 Kapella MC, Larson JL, Patel MK, et al. Subjective fatigue, influencing variables, and consequences in chronic obstructive pulmonary disease. Nurs Res 2006; 55: 10-17.

13 Woo K. A pilot study to examine the relationships of dyspnoea, physical activity and fatigue in patients with chronic obstructive pulmonary disease. J Clin Nurs 2000; 9: 526-533.

14 Breukink SO, Strijbos JH, Koorn M, et al. Relationship between subjective fatigue and physiological variables in patients with chronic obstructive pulmonary disease. Respir Med 1998; 92: 676-682.

15 Breslin E, van der Schans C, Breukink S, et al. Perception of fatigue and quality of life in patients with COPD. Chest 1998; 114: 958-964.

16 Kentson M, Todt K, Skargren E, et al. Factors associated with experience of fatigue, and functional limitations due to fatigue in patients with stable COPD. Ther Adv Respir Dis 2016; 10: 410-424.

17 Lewko A, Bidgood P, Jewell A, et al. A comprehensive literature review of COPD-related fatigue. Curr Respir Med Rev 2012; 8: 370-382.

18 Moher D, Liberati A, Tetzlaff J, et al. Preferred reporting items for systematic reviews and meta-analyses: the PRISMA statement. Ann Intern Med 2009; 151: 264-269.

19 Cohen J. Statistical Power Analysis for the Behavioral Sciences. 2nd edn. Hillsdale, NJ, Lawrence Erlbaum Associates, Publishers, 1998.

20 Vandevoorde J, Verbanck S, Gijssels L, et al. Early detection of COPD: a case finding study in general practice. Respir Med 2007; 101: 525-530.

21 Gift AG, Shepard CE. Fatigue and other symptoms in patients with chronic obstructive pulmonary disease: do women and men differ? J Obstet Gynecol Neonatal Nurs 1999; 28: 201-208.

22 Walke LM, Gallo WT, Tinetti ME, et al. The burden of symptoms among community-dwelling older persons with advanced chronic disease. Arch Intern Med 2004; 164: 2321-2324.

23 Walke LM, Byers AL, Tinetti ME, et al. Range and severity of symptoms over time among older adults with chronic obstructive pulmonary disease and heart failure. Arch Intern Med 2007; 167: 2503-2508.

24 Yang Y, Li Q, Mao J, et al. Fatigue and health-related quality of life among patients with chronic obstructive pulmonary disease in China. Clin Respir J 2020; 14: 109-115.

25 Valderramas S, Camelier AA, Silva SA, et al. Reliability of the Brazilian Portuguese version of the fatigue severity scale and its correlation with pulmonary function, dyspnea, and functional capacity in patients with COPD. J Bras Pneumol 2013; 39: 427-433.

26 Blinderman CD, Homel P, Billings JA, et al. Symptom distress and quality of life in patients with advanced chronic obstructive pulmonary disease. J Pain Symptom Manage 2009; 38: 115-123.

27 Goertz YMJ, Spruit MA, Van 't Hul AJ, et al. Fatigue is highly prevalent in patients with COPD and correlates poorly with the degree of airflow limitation. Ther Adv Respir Dis 2019; 13: 1753466619878128. 
28 Theander K, Unosson M. Fatigue in patients with chronic obstructive pulmonary disease. J Adv Nurs 2004; 45: 172-177.

29 Andersson M, Stridsman C, Ronmark E, et al. Physical activity and fatigue in chronic obstructive pulmonary disease - a population based study. Respir Med 2015; 109: 1048-1057.

30 Stridsman C, Mullerova H, Skar L, et al. Fatigue in COPD and the impact of respiratory symptoms and heart disease - a population-based study. COPD 2013; 10: 125-132.

31 Stridsman C, Svensson M, Johansson Strandkvist V, et al. The COPD Assessment Test (CAT) can screen for fatigue among patients with COPD. Ther Adv Respir Dis 2018; 12: 1753466618787380.

32 Strandkvist $\mathrm{V}$, Andersson M, Backman $\mathrm{H}$, et al. Hand grip strength is associated with fatigue among men with COPD: epidemiological data from northern Sweden. Physiother Theory Pract 2020; 36: 408-416.

33 Antoniu SA, Apostol A, Boiculese LV. Extra-respiratory symptoms in patients hospitalized for a COPD exacerbation: prevalence, clinical burden and their impact on functional status. Clin Respir J 2019; 13: 735-740.

34 Antoniu SA, Petrescu E, Stanescu R, et al. Impact of fatigue in patients with chronic obstructive pulmonary disease: results from an exploratory study. Ther Adv Respir Dis 2016; 10(1): 26-33.

35 Baltzan M, Scott A, Wolkove N, et al. Fatigue in COPD: prevalence and effect on outcomes in pulmonary rehabilitation. Chron Respir Dis 2011; 8: 119-128.

36 Chen YW, Camp PG, Coxson HO, et al. A comparison of pain, fatigue, dyspnea and their impact on quality of life in pulmonary rehabilitation participants with chronic obstructive pulmonary disease. COPD 2018; 15: 65-72.

37 Wong CJ, Goodridge D, Marciniuk DD, et al. Fatigue in patients with COPD participating in a pulmonary rehabilitation program. Int J Chron Obstruct Pulmon Dis 2010; 5: 319-326.

38 Bentsen SB, Gundersen D, Assmus J, et al. Multiple symptoms in patients with chronic obstructive pulmonary disease in Norway. Nurs Health Sci 2013; 15: 292-299.

39 Elbehairy AF, Mclsaac $\mathrm{H}$, Hill E, et al. Impact of a specialized ambulatory clinic on refractory breathlessness in subjects with advanced COPD: a retrospective analysis. Respir Care 2020; 65: 444-454.

40 Kinsman RA, Yaroush RA, Fernandez E, et al. Symptoms and experiences in chronic bronchitis and emphysema. Chest 1983; 83: 755-761.

41 Yohannes AM, Dryden S, Hanania NA. The responsiveness of the Manchester Chronic Obstructive Pulmonary Disease Fatigue Scale to pulmonary rehabilitation. Ther Adv Chronic Dis 2019; 10: 2040622319882206.

42 Benzo RP, Kirsch JL, Dulohery MM, et al. Emotional intelligence: a novel outcome associated with wellbeing and self-management in chronic obstructive pulmonary disease. Ann Am Thorac Soc 2016; 13: 10-16.

43 Al Moamary MS, Tamim HM. The reliability of an Arabic version of the self-administered standardized chronic respiratory disease questionnaire (CRQ-SAS). BMC Pulm Med 2011; 11: 21.

44 Mollaoglu M, Fertelli T, Tuncay F. Fatigue and disability in elderly patients with chronic obstructive pulmonary disease (COPD). Arch Gerontol Geriatr 2011; 53: e93-e98.

45 Miravitlles M, Iriberri M, Barrueco M, et al. Usefulness of the LCOPD, CAFS and CASIS scales in understanding the impact of COPD on patients. Respiration 2013; 86: 190-200.

46 Paddison JS, Effing TW, Quinn S, et al. Fatigue in COPD: association with functional status and hospitalisations. Eur Respir J 2013; 41: 565-570.

47 Al-shair K, Kolsum U, Berry P, et al. Development, dimensions, reliability and validity of the novel Manchester COPD fatigue scale. Thorax 2009; 64: 950-955.

48 Reishtein JL. Relationship between symptoms and functional performance in COPD. Res Nurs Health 2005; 28 : 39-47.

49 Yeh ML, Chen HH, Liao YC, et al. Testing the functional status model in patients with chronic obstructive pulmonary disease. J Adv Nurs 2004; 48: 342-350.

50 Woo K. Physical activity as a mediator between dyspnea and fatigue in patients with chronic obstructive pulmonary disease. Can J Nurs Res 2000; 32: 85-98.

51 Borge CR, Wahl AK, Moum T. Association of breathlessness with multiple symptoms in chronic obstructive pulmonary disease. J Adv Nurs 2010; 66: 2688-2700.

52 Karakurt P, Unsal A. Fatigue, anxiety and depression levels, activities of daily living of patients with chronic obstructive pulmonary disease. Int J Nurs Pract 2013; 19: 221-231.

53 Crockett AJ, Cranston JM, Moss JR, et al. The impact of anxiety, depression and living alone in chronic obstructive pulmonary disease. Qual Life Res 2002; 11: 309-316.

54 Lin FJ, Pickard AS, Krishnan JA, et al. Measuring health-related quality of life in chronic obstructive pulmonary disease: properties of the EQ-5D-5L and PROMIS-43 short form. BMC Med Res Methodol 2014; 14: 78.

55 Todt K, Skargren E, Kentson M, et al. Experience of fatigue, and its relationship to physical capacity and disease severity in men and women with COPD. Int J Chron Obstruct Pulmon Dis 2014; 9: 17-25.

56 Meng NH, Chen FN, Lo SF, et al. Reliability and validity of the Taiwan (Mandarin Chinese) version of the chronic respiratory questionnaire. Qual Life Res 2011; 20: 1745-1751.

57 Boueri FM, Bucher-Bartelson BL, Glenn KA, et al. Quality of life measured with a generic instrument (Short Form-36) improves following pulmonary rehabilitation in patients with COPD. Chest 2001; 119: 77-84. 
58 Güell R, Casan P, Sangenís M, et al. Quality of life in patients with chronic respiratory disease: the Spanish version of the Chronic Respiratory Questionnaire (CRQ). Eur Respir J 1998; 11: 55-60.

59 Lee J, Nguyen HQ, Jarrett ME, et al. Effect of symptoms on physical performance in COPD. Heart Lung 2018; 47: 149-156.

60 Calik-Kutukcu E, Savci S, Saglam M, et al. A comparison of muscle strength and endurance, exercise capacity, fatigue perception and quality of life in patients with chronic obstructive pulmonary disease and healthy subjects: a cross-sectional study. BMC Pulm Med 2014; 14: 6.

61 Deng G, Liu F, Zhong Q, et al. The effect of non-pharmacological staged interventions on fatigue and dyspnoea in patients with chronic obstructive pulmonary disease: a randomized controlled trial. Int $J$ Nurs Pract 2013; 19: 636-643.

62 Nguyen HQ, Donesky-Cuenco D, Carrieri-Kohlman V. Associations between symptoms, functioning, and perceptions of mastery with global self-rated health in patients with COPD: a cross-sectional study. Int $J$ Nurs Stud 2008; 45: 1355-1365.

63 Tsai CL, Hodder RV, Page JH, et al. The short-form chronic respiratory disease questionnaire was a valid, reliable, and responsive quality-of-life instrument in acute exacerbations of chronic obstructive pulmonary disease. J Clin Epidemiol 2008; 61: 489-497.

64 McCarley C, Hanneman SK, Padhye N, et al. A pilot home study of temporal variations of symptoms in chronic obstructive lung disease. Biol Res Nurs 2007; 9: 8-20.

65 Boer LM, Bischoff EW, Borgijink X, et al. "Exacerbation-free time" to assess the impact of exacerbations in patients with chronic obstructive pulmonary disease (COPD): a prospective observational study. NPJ Prim Care Respir Med 2018; 28: 12.

66 Jones PW, Brusselle G, Dal Negro RW, et al. Health-related quality of life in patients by COPD severity within primary care in Europe. Respir Med 2011; 105: 57-66.

67 Alibasic E, Skopljak A, Cengic A, et al. Efficacy of carbocisteine in the treatment of chronic obstructive pulmonary disease and impact on the quality of life. Med Glas (Zenica) 2017; 14: 182-188.

68 Parreira VF, Kirkwood RN, Towns M, et al. Is there an association between symptoms of anxiety and depression and quality of life in patients with chronic obstructive pulmonary disease? Can Respir J 2015; 22: 37-41.

69 Hanania NA, Mullerova H, Locantore NW, et al. Determinants of depression in the ECLIPSE chronic obstructive pulmonary disease cohort. Am J Respir Crit Care Med 2011; 183: 604-611.

70 Martin LL. Validity and reliability of a quality-of-life instrument: the chronic respiratory disease questionnaire. Clin Nurs Res 1994; 3: 146-156.

71 Moody L, McCormick K, Williams AR. Psychophysiologic correlates of quality of life in chronic bronchitis and emphysema. West J Nurs Res 1991; 13: 336-352.

72 Kallivoka M, Alikari V, Spetsioti S, et al. Fatigue and quality of life after pulmonary rehabilitation program. Pneumon 2019; 32: 72-80.

73 Arikan H, Savci S, Calik-Kutukcu E, et al. The relationship between cough-specific quality of life and abdominal muscle endurance, fatigue, and depression in patients with COPD. Int J Chron Obstruct Pulmon Dis 2015; 10: 1829-1835.

74 Vigil L, Güell M, Morante F, et al. The validity and sensitivity to change of the Spanish self-administered version of the chronic respiratory questionnaire (CRQ-SAS). Arch Bronconeumol 2011; 47: 343-349.

75 Vercoulen JHMM, Alberts M, Bleijenberg G. De Checklist Individual Strength (CIS). Gedragstherapie 1999; 32 131-136.

76 Vercoulen JHMM, Swanink CMA, Fennis JFM, et al. Dimensional assessment of chronic fatigue syndrome. J Pychosom Res 1994; 38: 383-392.

77 Worm-Smeitinka M, Gielissen M, Blootc L, et al. The assessment of fatigue: psychometric qualities and norms for the Checklist individual strength. J Psychosom Res 2017; 98: 40-46.

78 Dittner AJ, Wessely S, Brown RG. The assessment of fatigue: a practical guide for clinicians and researchers. J Psychosom Res 2004; 56: 157-170.

79 Yellen SB, Cella DF, Webster K, et al. Functional Assessment of Chronic Illness Therapy Fatigue Scale relative to other instrumentation in patients with rheumatoid arthritis. $J$ Rheumatol 2005; 32: 811-819.

80 Antoniu SA, Ungureanu D. Measuring fatigue as a symptom in COPD: from descriptors and questionnaires to the importance of the problem. Chron Respir Dis 2015; 12: 179-188.

81 Bruera E, Kuehn N, Miller MJ. The edmonton symptom assessment system (ESAS): a simple method for the assessment of palliative care patients. J Palliat Care 1991; 7: 6-9.

82 Wijkstra PJ, TenVergert EM, van Altena R, et al. Reliability and validity of the chronic respiratory questionnaire (CRQ). Thorax 1994; 49: 465-467.

83 Oga T, Nishimura K, Tsukino M, et al. Longitudinal changes in health status using the chronic respiratory disease questionnaire and pulmonary function in patients with stable chronic obstructive pulmonary disease. Qual Life Res 2004; 13: 1109-1116. 
84 Krupp LB, LaRocca N, Muir-Nash J, et al. The Fatigue Severity Scale. Application to patients with multiple sclerosis and systemic lupus erythematosus. Arch Neurol 1989; 46: 1121-1123.

85 Dittner AJ, Wessely SC, Brown RG. The assessment of fatigue. A practical guide for clinicians and researchers. J Psychosom Res 2004; 56: 157-170.

86 Ware JE Jr, Sherbourne CD. The MOS 36-Item Short-Form Health survey (SF-36): I. Conceptual framework and item selection. Med Care 1992; 30: 473-483.

87 Lee KA, Hicks G, Nino-Murcia G. Validity and reliability of a scale to assess fatigue. Psychiatry Res 1990; 36 : 291-298.

88 Alghadir AH, Anwer S, Iqbal A, et al. Test-retest reliability, validity, and minimum detectable change of visual analog, numerical rating, and verbal rating scales for measurement of osteoarthritic knee pain. $J$ Pain Res 2018; 11: 851-856.

89 Smets EMA, Garssen B, Bonke B, et al. The multidimensional fatigue inventory (MFI) psychometric qualities of an instrument to assess fatigue. J Psychosom Res 1995; 39: 315-325.

90 Reeves WC, Wagner D, Nisenbaum R, et al. Chronic Fatigue Syndrome - a clinically empirical approach to its definition and study. BMC Med 2005; 3: 19.

91 Revicki DA, Meads DM, McKenna SP, et al. COPD and Asthma Fatigue Scale (CAFS): development and psychometric assessment. Health Outcomes Res Med 2010; 1: 5-16.

92 Chang VT, Hwang SS, Feuerman M, et al. The Memorial Symptom Assessment Scale Short Form (MSAS-SF). Validity and reliability. Cancer 2000; 89: 1162-1171.

93 Mendoza TR, Wang XS, Cleeland CS, et al. The rapid assessment of fatigue severity in cancer patients - use of the Brief Fatigue Inventory. Cancer 1999; 85: 1186-1196.

94 McNair D, Lorr M, Droppleman L. The Manual for the Profile of Mood States. San Diego, CA, Educational and Industrial Testing Service, 1992.

95 Goërtz YMJ, Looijmans M, Prins JB, et al. Fatigue in patients with chronic obstructive pulmonary disease: protocol of the Dutch multicentre, longitudinal, observational FAntasTIGUE study. BMJ Open 2018; 8 : e021745. 